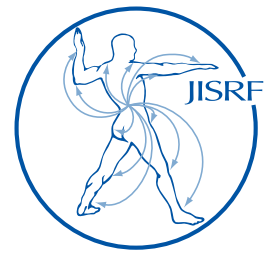

Check for updates

\title{
Margin-of-safety Algorithm Used with EOS Imaging to Interpret MHRA Warning for 46-48mm MOM Arthroplasty
}

Clarke $I^{1}$, Lazennec $J^{2}$

\section{Abstract}

The Medical Healthcare Products Regulatory Agency (MHRA June-2015) warned of higher risks with 46-48mm sizes of BHR hip resurfacing arthroplasty (HRA). The most common condemnation of adverse results in MOM bearings has been termed edge loading. We originally developed a margin-ofsafety (MOS) algorithm to define edge loading of cups in simulator studies. This method integrated simulator wear-patterns with respect to cup diameters and cup designs. The algorithm's simplicity lay in the fact that with wear-patterns and rim-profile angles predetermined, the only input required was the cup inclination-angle. The algorithm demonstrated that the margin-of-safety decreased in smaller cups due to the tribo-mechanics of spherical CoCr bearings, a previously unrecognized feature. For the $46 \mathrm{~mm}$ and 48mm cups highlighted in the MHRA alert, the critical cup inclinations where edge-wear became a risk occurred at $65-66^{\circ}$, revealing an insignificant difference with respect to diameters. The MOS-algorithm also indicated that lower lateral-inclination angles were particularly beneficial, i.e. a $46 \mathrm{~mm}$ cup positioned at $50^{\circ}$ inclination would exhibit a higher margin of safety than either $48 \mathrm{~mm}$ or $50 \mathrm{~mm}$ sizes positioned at $55^{\circ}$ inclination. This evidence supported clinical studies that recommended BHR cup inclinations up to $50-55^{\circ}$ and lower as optimal for reducing metal-ion concentrations. In a patient with normal spine mobility, our EOS imaging demonstrated that the inclination in the $46 \mathrm{~mm}$ cup steepened by $9^{\circ}$ from standing to the seated position while margin-of-safety was reduced by $50 \%$. Our 2 nd patient with a stiff spine sat with the same component orientations as in his standing posture. Thus MOM impingement and subluxation in different functional postures may also provoke rim-damage mechanisms. Here the combination of EOS imaging and the MOS-algorithm may aid understanding of such risks. Thus the margin-of-safety algorithm confirmed and helped explained the relative risks in the $46 \mathrm{~mm}$ and $48 \mathrm{~mm}$ cups highlighted

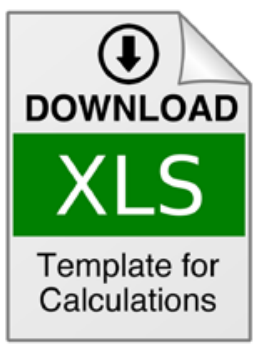

1 Department of Orthopedics, Loma Linda University Medical Center, Loma Linda CA 92354 US (Direct reprint requests to Ian Clarke)

2 Department of Orthopaedics, La Pitie Hospital, UPMC University, Paris, France
C 2015 Clarke, Lazennec. All rights reserved

Authors retain copyright and grant the journal right of first publication with the work. Reconstructive Review follows the Creative Commons Attribution-NonCommercial CC BY-NC. This license allows anyone to download works, build upon the material, and share them with others for non-commercial purposes as long as they credit the senior author, Reconstructive Review, and the Joint Implant Surgery \& Research Foundation (JISRF). An example credit would be: "Courtesy of (senior author's name), Reconstructive Review, JISRF, Chagrin Falls, Ohio". 
by the MHRA. The algorithm's stratification by cup rimprofile, inclination angle and cup diameter may assist the surgeon determine which patients may be more at risk for edge wear with the smaller BHR cups. The ARC, CPR and MOS algorithms can be downloaded here (Excel file).

Keywords: BHR Resurfacing Arthroplasty, cup inclination, edge wear, MHRA alert, EOS, MOM

Level of Evidence: AAOS Therapeutic Level V

\section{Introduction}

Clinical studies of metal on metal (MOM) bearings used in hip resurfacing arthroplasty and total hip arthroplasty frequently described high rates of failure. [1-4] The most common condemnation of MOM performance has been termed "edge-loading". [1,5-12] Studies implicated small MOM diameters, sub-hemispherical cup designs, surgical positioning, and hip-joint excursion. Nevertheless the BHR resurfacing system continues to receive acclaim as very successful when applied correctly to young patients with the right indications, even in patients with the small BHR devices. [13-15] However, a recent Medical Device Alert by the Medical Healthcare Products Regulatory Agency (MHRA, June 2015, UK) singled out female patients and 46-48mm BHR devices as representative of unacceptable risks but with no guidelines provided (Fig. 1). Thus the surgeon may have a dilemma in determining

\section{thoV.UK}

\section{Medical safety alert \\ Metal-on-metal (MoM) hip replacements - guidance on implantation and patient management

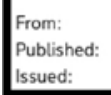 \\ Medicines and Healthcare products Regulatory Agency 25 June 2015 \\ 25 June 2015 \\ - Do not implant BHR devices in: \\ - female patients \\ - patients requiring femoral heads sized $46 \mathrm{~mm}$ or smaller \\ - Only use $48 \mathrm{~mm}$ BHR heads in the specific circumstance of intra-operative downsizing from a pre-operatively templated $50 \mathrm{~mm}$ to a measured $48 \mathrm{~mm}$ at the time of surgery \\ - Return all unused BHR femoral heads sized $46 \mathrm{~mm}$ and smaller and their corresponding acetabular and dysplasia cups to the manufacturer \\ - Follow up patients implanted with BHR hips that fall within the scope of this medical device alert ie: \\ - all symptomatic patients \\ - all female patients \\ - all patients implanted with head sizes $46 \mathrm{~mm}$ or smaller}

Fig.1. Medical Healthcare Products Regulatory Agency (MHRA) issued a medical device alert (MDA-2015/024, 25th June 2015) identifying higher risks with BHR sizes $46-48 \mathrm{~mm}$

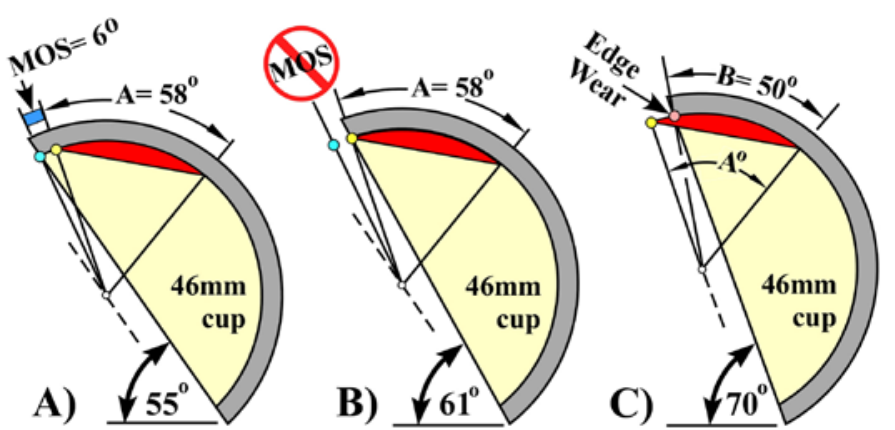

Fig. 2. Effect of cup inclination on wear-pattern (angle-A) and margin-of-safety (MOS), A) at $55^{\circ}$ inclination the cup wear-pattern has $a 58^{\circ}$ arc and MOS has a $6^{\circ}$ arc, B) adding $6^{\circ}$ additional inclination reduces MOS to zero, and C) adding another $9^{\circ}$ inclination reduces the cup wear-pattern to a $50^{\circ}$ arc and edge wear presents. This edge-wear definition would be $E W=9 / 58=16 \%$ ".

which of his patients with smaller BHR devices may be at risk.

The key to assessing edge-wear lies in defining the 'margin for error' [9] or, as will be termed here, the 'margin-of-safety' (Fig. 2). During the bearing's run-in phase, the cup wear-pattern grows rapidly, typically to greater than $400 \mathrm{~mm}^{2}$ area. $[16,17]$ As long as this habitual wearpattern is separated from the cup rim by an adequate margin-of-safety (MOS), edge wear is unlikely (Figs. 2a, 3a). At a steeper angle the margin-of-safety decreases to zero and places the patient at risk for edge wear (Fig. 2b). At even steeper angles the cup rim will cross over the habitual wear-pattern area and edge wear ensues (Figs. 2c, $3 b)$. This is believed to create severe stress-concentrations, compromise fluid-film lubrication, and thereby contribute to extreme wear. $[6,10,11,18,19]$ The Petersen Tribology Laboratory of Loma Linda University (LLU) developed a margin-of-safety algorithm that integrated simulator wearpatterns with respect to cup diameters and cup designs. The

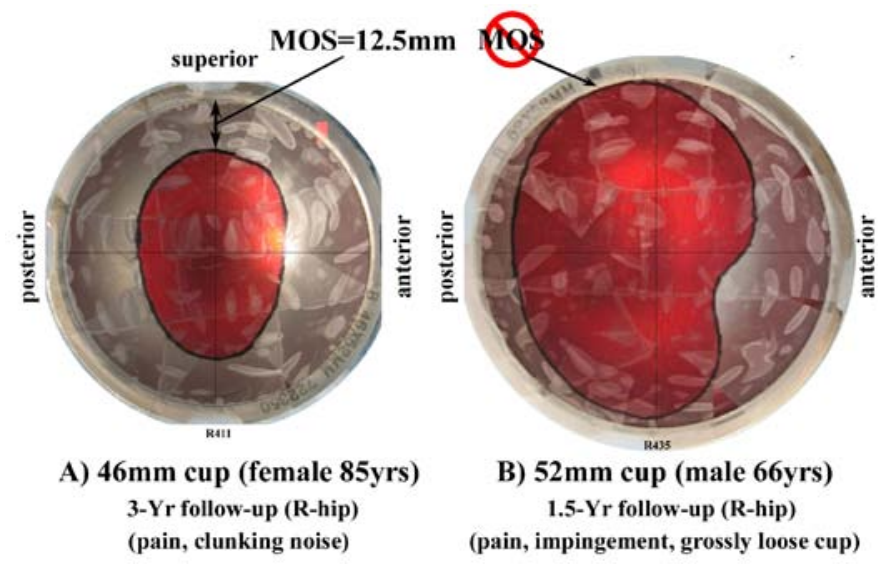

Fig. 3. Wear-patterns (colored red for photography) in MOM retrieval studies showing, (a) margin of safety superior to central wear-pattern, and $(b)$ wear-pattern juxtaposed to cup rim indicating edge-wear. 
algorithm has been used to validate edge-loading in studies of steep cup scenarios. [20] While size of cup wear-patterns appeared to be an important parameter, this was not considered in prior studies. Clinical methods for assessing cup coverage have included the "Arc of Cover" distance [9] and the "Contact Patch to Rim" (CPR) distance. [1] These concepts measured the distance from the cup rim to either the vertical reference plane or to a $14^{\circ}$ medially-directed axis, respectively (Fig. 4a). A third method termed "Contact Patch Edge to Rim" distance (CPER) combined a $14^{\circ}$ medially-directed reference axis with a "contact patch" calculation (Fig. 4b). [6] While such measurements provided stratification of risk, [6,21-23] they did not provide the surgeon with the neccessary details to assess risk of edge-wear directly.

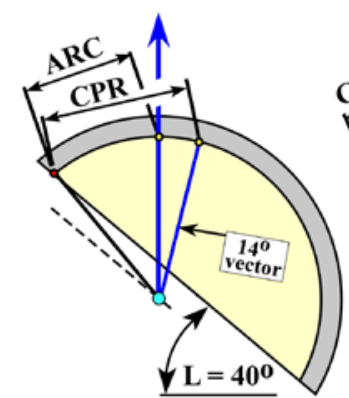

A) ARC and CPR distances de Haan et al (2008) Langton et al (2009)

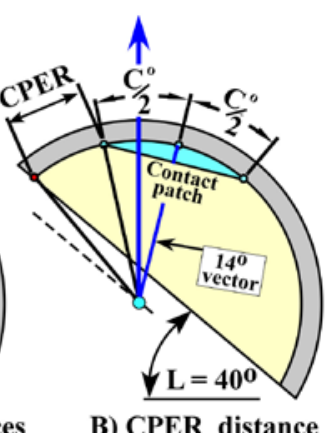

B) CPER distance
Fig. 4. Schematic of methods used to describe cup coverage on antero-posterior images, a) "Arc of Cover" (ARC) [9] and "Contact Patch to Rim" (CPR) [1] distances, where 'ARC' defines a chord to be comparable to CPR-distance method, and b) "Contact Patch Edge to Rim" (CPER) [6].

There has also been little understanding of how patient postures change the position of artificial hip-joints. The majority of measurements have been made from radiographic or CT images taken with the patient in the supine position. However, hip dislocation is a frequent mode of failure and the sitting position is one where most impingements and posterior dislocations occur. At La Pitie Hospital (Paris, France), the orthopedic group developed EOS imaging (author JYL) to investigate various patient postures. The EOS ${ }^{\mathrm{TM}}$ imaging system is capable of simultaneously capturing two orthogonal antero-posterior (AP) and lateral images, thus typically providing full pelvic visualization in standing, sitting, and other positions. [24,25] The first objective of this report was to study the margins-ofsafety (MOS) in 46-48mm diameter BHR mentioned in the MHRA warning. The conventional ARC and CPR methods were also compared (Fig. 4a). The second objective was to compare MOS and CPR data for standing and sitting positions in two patients, both with 46mm diameter MOM.

\section{Methods}

To avoid confusion with "contact patch" data and other commonly used terms (Fig. 4), the wear area produced in hip simulator studies will be defined as the Cup Area Pattern (CAP). CAP areas in MOM simulator studies typically ranged $411-480 \mathrm{~mm}^{2}$ by the end of the 5-million cycle tests. $[16,17,26]$ The corresponding wear-pattern angles (Fig. 2: angle-A) were calculated using standard equations for spherical geometry. These were plotted with respect to cup diameter and extrapolated by linear regression to cover the $36-60 \mathrm{~mm}$ diameter range. The extent of cup rim-coverage is also believed to be an important parameter. [1,8-12] In this study we utilized the rim-profile angle (Fig. 5: P) to define loss of coverage in the load-bearing area of the cup. Cup-profile angles $(\mathrm{P})$ were derived from published cupface angles (F) provided for five MOM systems [6] and calculated using,

\section{Equation-1 (Fig. 5): $2 * \mathrm{P}=180-\mathrm{F}$}

The rim profile angles were extrapolated over the 36$60 \mathrm{~mm}$ diameter range by linear-regression techniques. CPR and MOS data were calculated using the $14^{\circ}$ medially-directed vector. [1] For a cup positioned with lateral-inclination L-angle (Fig. 5) the summation follows as,

\section{Equation-2 (Fig. 5): \\ $\mathrm{L}+\mathrm{P}+\mathrm{MOS}+\mathrm{A} / 2=104^{\circ}$}

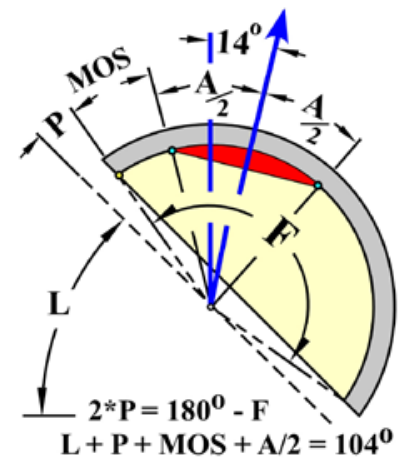

\section{Fig. 5. Illustration of cup geometry defining inclination angle $(L)$, rim- profile angle $(P)$ and wear- pattern angle $(A)$ with respect to a $14^{\circ}$ medially directed load vector.}

Note with resultant loading in simulator studies being in the vertical plane, equation-2 would simply be summated to $90^{\circ}$. The MOS-algorithm also provided a definition for edge-wear (EW), whereby,

Equation-3 (Figs. 2b, c): $\mathrm{EW} \%=100 *(\mathrm{~A}-\mathrm{B}) / \mathrm{A}$ 
The critical cup inclination angle $(* \mathrm{~L})$ with marginof-safety diminished to zero can be determined by setting MOS=0 in equation- 2 ,

\section{Equation-4 Critical inclination (Fig. 2b):

$$
* \mathrm{~L}=104^{\circ}-(\mathrm{P}+\mathrm{A} / 2)
$$

Clinical studies of cup coverage have used varied criteria (Fig. 4) and therefore equation-2 can simply be extended as follows,

\section{Equation-5 (Figs. 4a):$$
\mathrm{L}+\mathrm{P}+\mathrm{ARC}=90^{\circ}[9]
$$ \\ Equation-6: (Figs. 4a, 5):$$
\mathrm{L}+\mathrm{P}+\mathrm{CPR}=104^{\circ}[1]
$$ \\ Equation-7: (Fig. 4b):

$$
\mathrm{L}+\mathrm{P}+\mathrm{CPER}+\mathrm{C} / 2=104^{\circ}[6]
$$

Using angles for margin-of-safety calculations greatly simplifies the analysis (Fig. 5). As required, MOS and CPR angles can be converted to 'distance' measurements,

\section{Equation-8a:}

MOS distance $(\mathrm{mm})=\mathrm{DIA} * \sin (\mathrm{MOS} / 2)$

\section{Equation-8b: \\ CPR distance $(\mathrm{mm})=\mathrm{DIA} * \sin (\mathrm{CPR} / 2)$}

A set of sample calculations are included for ARC, CPR and MOS indices (Table 1) - the template for ARC, CPR and MOS calculations can be downloaded here (Excel file). It is noted that the original equation for "Arc of Cover" calculated the distance along the cup surface, i.e. length of the circular arc. [9] In this study, the ARC distance (equation-5) defined the chord of a circle in order to be compatible with the CPR method (Fig. 4). The CPER innovation (equation-7) added contact-patch size, which reduced the rim-distance prediction compared to CPR data. However, following the run-in wear process, patient hip-function will have enlarged the wear-pattern area much beyond the size of the contact patch. [16]

The EOS imaging presents patients in various functional positions for analysis of pelvic and femoral rotations and for comparison of implant positions. Differences between standing and sitting postures were compared in two patients, one with normal spinal mobility and the second with considerable stiffness due to spinal pathology. Both had 46mm THA (Metasul ${ }^{\mathrm{TM}}$, Zimmer, Warsaw IN) with a $5^{\circ}$ rim-profile angle $(\mathrm{P})$. Cup inclination angles and $\mathrm{CPR}$ distances were calculated and compared with the MOS-algorithm for sitting versus standing postures.

\section{Results}

The data from simulator studies demonstrated that wear-pattern angles decreased linearly with increasing cup diameter (Fig. 6). The wear pattern in a 36mm BHR-type cup had a $66.7^{\circ}$ angle, which decreased to $58.2^{\circ}$ in a $46 \mathrm{~mm}$ cup and to $56.6^{\circ}$ in a $48 \mathrm{~mm}$ cup. The largest cup considered $(60 \mathrm{~mm})$ had the smallest wear-pattern angle $\left(46.4^{\circ}\right)$,

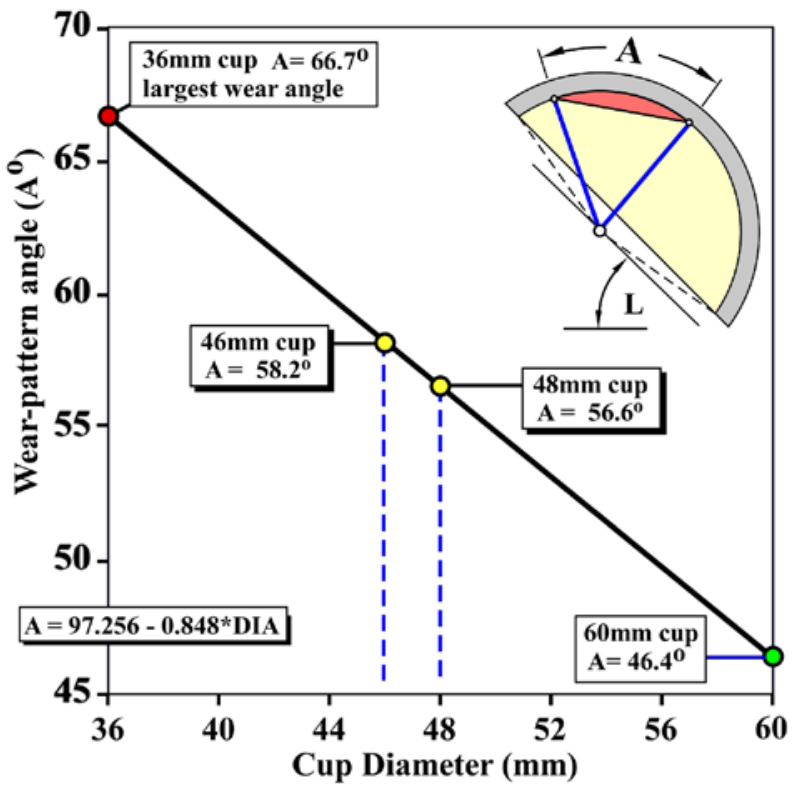

Fig. 6. Trending of wear-pattern angles (A) derived from linear regression of data from hip simulator wear-patterns. [20]

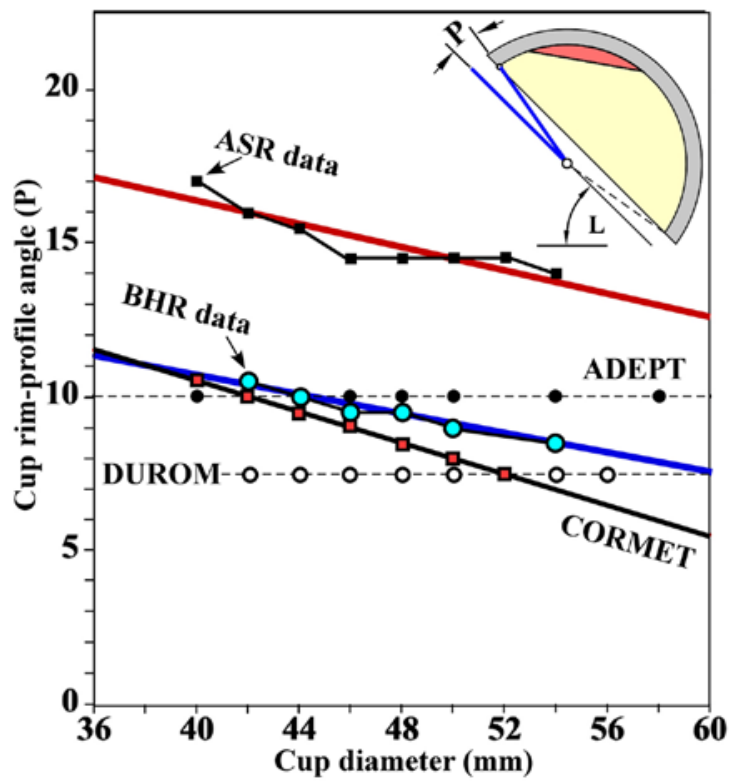

Fig. 7. Trending of rim-profile angles $(P)$ derived from data on cupface angles $(F) .[6]$ 
which compared to the $36 \mathrm{~mm}$ cup, represented an overall reduction of $20.3^{\circ}$.

The rim-profile angle $(\mathrm{P})$ defined how much hemispherical coverage was reduced in the load-bearing region (Fig. 7). These data will be labeled 'BHR-type' since some values may not reflect the vendor's actual specification (Table 1). The CORMET design provided the most coverage while the ASR provided least. The ADEPT and DUROM cups had constant profile angles whereas the ASR, BHR and CORMET profile angles decreased linearly with increasing diameter (Fig. 7).

Differences produced by wear-pattern and rim-profile angles were illustrated by comparing $46 \mathrm{~mm}$ and $56 \mathrm{~mm}$ cups (Fig. 8). Wear-pattern areas covered 418 and 458 $\mathrm{mm}^{2}$ in the small and large cups, respectively. However the wear-pattern angle was larger $\left(58.2^{\circ}\right)$ in the small cup than in the large cup $\left(49.8^{\circ}\right)$. The rim-profile angle $(\mathrm{P})$ was also larger in the smaller cup $\left(9.7^{\circ}\right.$ vs $\left.8.1^{\circ}\right)$. The combined effect of these angles (Fig. 8) reduced the safety margin in the small cup $\left(\mathrm{MOS}=15.2^{\circ}\right)$ by $5.8^{\circ}$ compared to the large cup $\left(\mathrm{MOS}=21^{\circ}\right)$.

A)

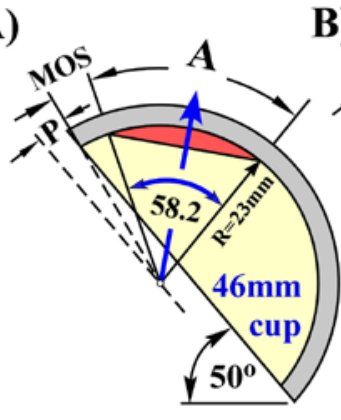

Wear area $=418 \mathrm{~mm}^{2}$

Wear-pattern angle $(A)=58.2^{\circ}$ Rim-profile angle $(P)=9.7^{\circ}$ margin-of-safety $=15.2^{\circ}$

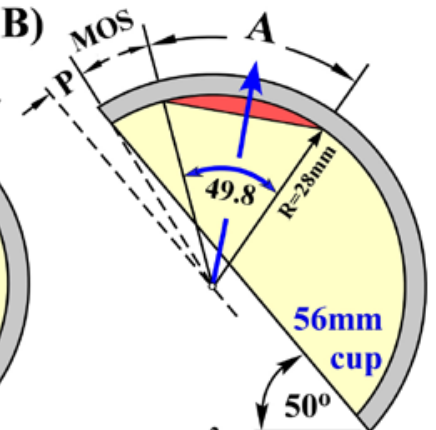

Wear area $=458 \mathrm{~mm}^{2}$

Wear-pattern angle $(A)=49.8^{\circ}$ Rim-profile angle $(\mathrm{P})=8.1^{\circ}$ margin-of-safety $=21^{\circ}$

Fig. 8. Comparison of wear-pattern angles (A) and margins-of-safety (MOS) produced in $46 \mathrm{~mm}$ and $56 \mathrm{~mm}$ cups at same inclination angle.

Comparing cups at $65^{\circ}$ inclination the methods predicted that safety margins increased linearly with component size (Fig. 9a). The ARC and CPR methods had similar slope but differed in magnitude due to the $14^{\circ}$ difference in their reference axes (Fig. 4). The CPER had the same reference axis as CPR method but subtracted the half-width of the contact patch, this reduction making it similar in magnitude to the ARC method. The MOS-algorithm revealed that $36-46 \mathrm{~mm}$ diameter cups had edge-wear while the $48 \mathrm{~mm}$ size achieved a safety margin represented by only $1.3^{\circ}$ (Fig. 9a). The MOS trend showed the lowest magnitude but steepest slope due to the inclusion of simulator wear-patterns. The critical inclination angles (equation-4) were $65.2^{\circ}$ and $66.3^{\circ}$ for 46 and $48 \mathrm{~mm}$ diameters respectively (Fig. 9b). Comparing MOM diameters and inclina-
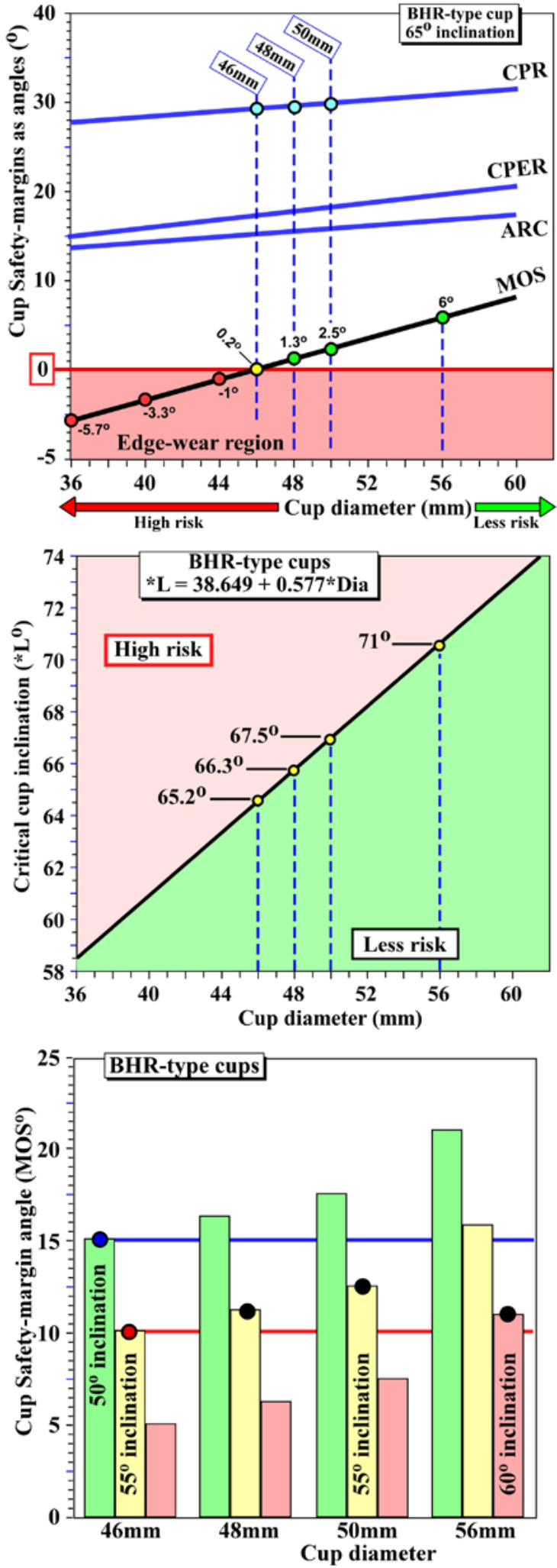

Fig. 9. Comparisons of safety predictions in BHR-type cups,

(a) ARC, CPER, CPR and MOS angles for 36-60mm diameter cups, all at $65^{\circ}$ cup inclination,

(b) Critical inclination angles (equation-4) predicted for 36$60 \mathrm{~mm}$ diameter cups

(c) Margins of safety predictions (MOS, angles) for small cups sizes 46-50mm versus the $56 \mathrm{~mm}$ size and compared using cup inclinations 50, 55 and $60^{\circ}$. 
tion angles, the $46 \mathrm{~mm}$ cup at $50^{\circ}$ inclination exhibited a greater safety-margin than the $48 \mathrm{~mm}$ and $50 \mathrm{~mm}$ cups at $55^{\circ}$ inclination. At the same inclination, the $46 \mathrm{~mm}$ cup exhibited a safety-margin only slightly lower than $48 \mathrm{~mm}$ and $50 \mathrm{~mm}$ sizes. The MOS-algorithm predicted that rim distances in 48 and $50 \mathrm{~mm}$ cups would be $0.5 \mathrm{~mm}$ and $1.1 \mathrm{~mm}$, respectively (Fig. 10). The CPR method produced 11.6-12.3mm distances for critical cup sizes $46-48 \mathrm{~mm}$, which as indicated were above the $10 \mathrm{~mm}$ clinical threshold (Fig. 10).

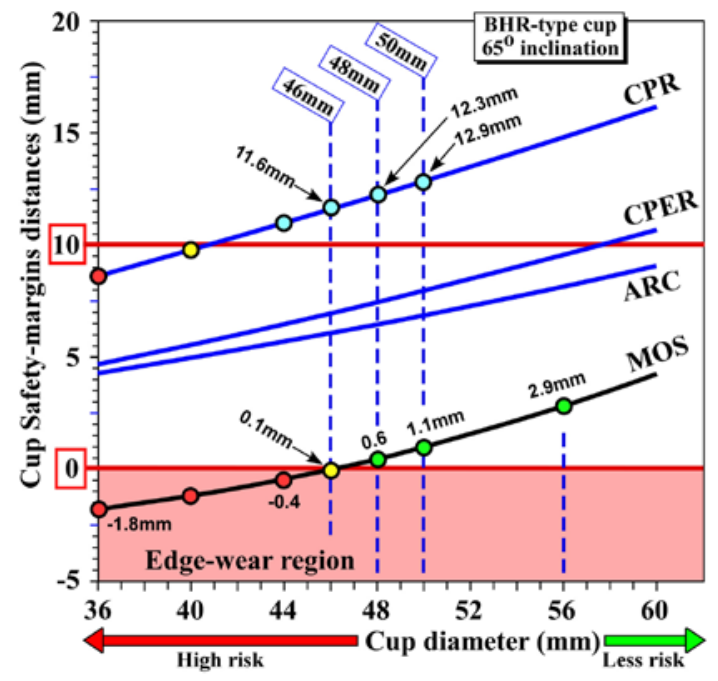

Fig. 10. Comparison of safety margins (distances) predicted by four methods (ARC, CPER, CPR, MOS) for a cup inclination of $65^{\circ}$.

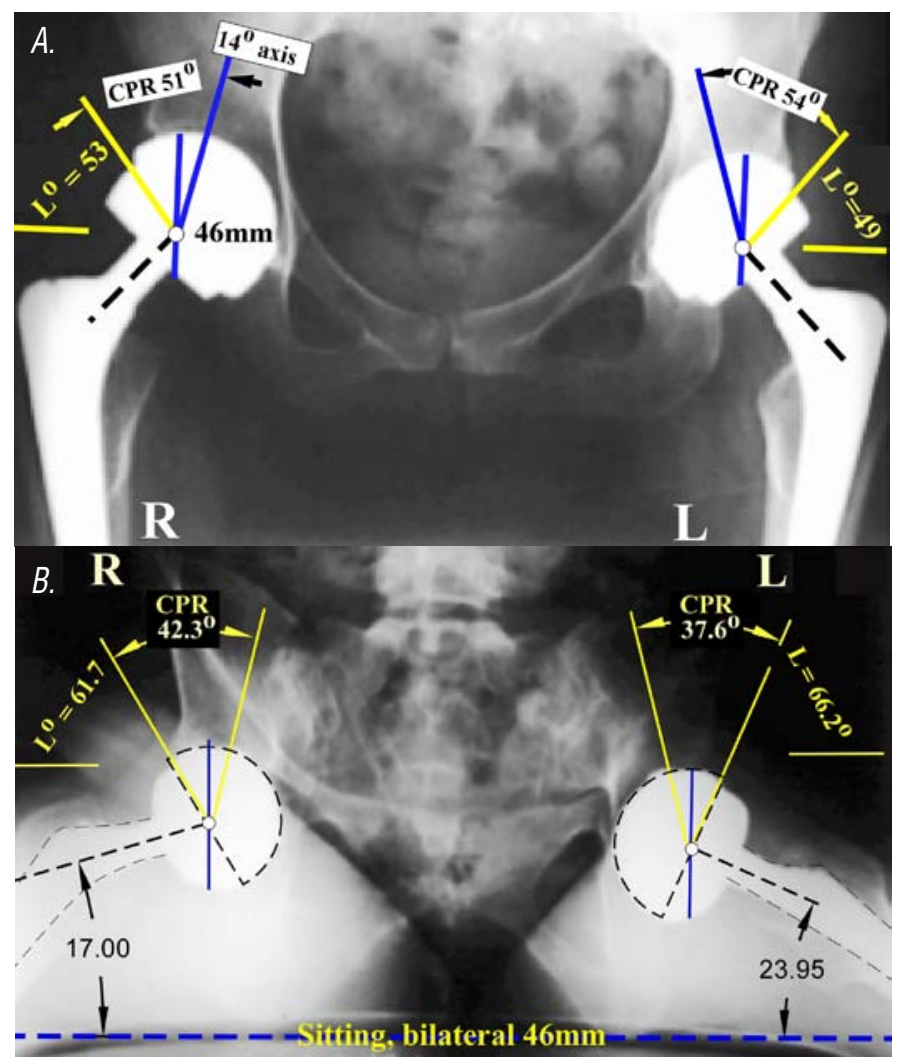

Fig. 11. EOS images for case with bilateral $46 \mathrm{~mm}$ THA and good pelvic mobility in (a) standing and (b) sitting.
In standing posture, EOS imaging revealed that the cup in the right hip of patient- 1 had a $53^{\circ}$ lateral inclination that increased to $62^{\circ}$ in sitting (Fig. 11). The CPR angles were correspondingly reduced from $51^{\circ}$ to $42^{\circ}$ and calculated MOS angles reduced from $16.6^{\circ}$ to $8.1^{\circ}$. In contrast, patient- 2 had essentially the same cup inclinations in both standing and sitting positions and thus CPR and MOS angles varied little (Fig. 12).

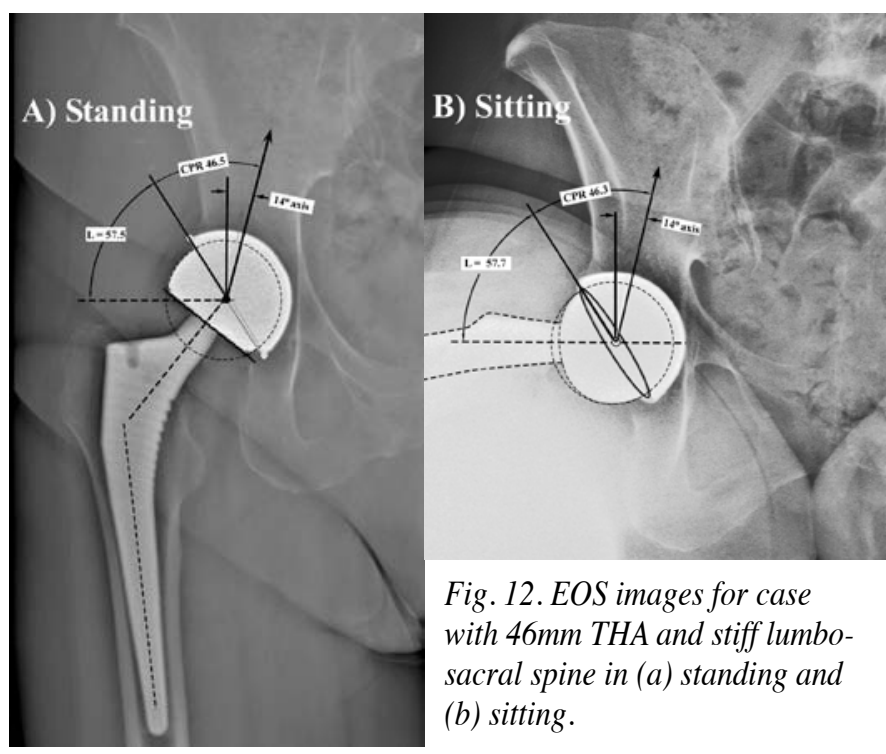

\section{Discussion}

The margin-of-safety method appears to be the first to integrate wear-patterns and cup rim-profiles to define "edge-wear". Its simplicity lies in the fact that using the predetermined wear-patterns and rim-profile angles, the only input required is cup inclination (Table 1). This algorithm revealed that critical cup inclinations, where edgewear becomes a risk, were defined solely by cup-profile and wear-pattern angles (equation-4). The former represents the cup-design parameter while the latter represents tribo-mechanics of spherical CoCr bearings. For the BHR cups highlighted in the recent MHRA warning, the MOS algorithm predicted that the $46 \mathrm{~mm}$ cup was most at risk at $65^{\circ}$ and higher inclinations while the difference in safety margin between 46 and $48 \mathrm{~mm}$ cups was represented by only $1.1^{\circ}$. Thus cup diameters appeared to be a relatively weak indicator of safety margin. The MOS-algorithm predicted that the margin of safety would actually be higher in a $46 \mathrm{~mm}$ cup positioned with $5^{\circ}$ lower inclination than in $48 \mathrm{~mm}$ or $50 \mathrm{~mm}$ size cups. Thus the margin-of-safety algorithm confirmed and explained the relative risks of $46 \mathrm{~mm}$ and $48 \mathrm{~mm}$ cups highlighted in the MHRA alert. Conversely, for a $46 \mathrm{~mm}$ cup angled $5^{\circ}$ higher than its critical incli- 
nation (in Fig. 9b), the resulting definition for edge wear (equation-3) would simply show that $\mathrm{A}-\mathrm{B}=5^{\circ}$ where angle-A $=58.2^{\circ}$ (Table 1) and EW\% $=5 / 58.2=8.6 \%$.

The margin-of-safety algorithm has been validated in hip simulator tests. $[20,27]$ However for clinical applications there are limitations to a mathematical depiction of edge-wear. The main assumption was that cup wear-patterns in hip simulators would be predictive of those in patients. It is to be anticipated that the $\mathrm{CoCr}$ tribo-mechanics in spherical bearings will be similar in vivo and in vitro. The major difference is that component positioning and hip functions are well defined in a simulator test and also nonvariant. In contrast, surgical positioning of femoral and acetabular components and subsequent hip function represent a complex set of variables. In particular the head:neck ratios in the resurfaced hip joints may have variable effects such as impingement and subluxation. [28] In this regard our MOM retrieval studies documented that cup wear-patterns were much larger in failed MOM cases (Fig. 3b). [29]

Clinical studies of BHR cases recommended cup inclinations up to $50-55^{\circ}$ as optimal for reducing the metal-ion concentrations but also indicated that lower angles could risk anterior impingement. [1,30] The $46 \mathrm{~mm}$ and $48 \mathrm{~mm}$ BHR-type cups described here demonstrated critical cup inclinations at $65-66^{\circ}$ (equation-4). This evident shift of perhaps $10^{\circ}$ may represent the difference between mathematical precision and clinical reality. The MOS-algorithm defined the proximity of the wear pattern to the cup rim at varied 'inclination' angles. Other mathematical methods integrated the angles of cup anteversion and lateral-inclination to provide a more complete component description. $[6,23]$ However, all current methods were based on an assumption of a $14^{\circ}$ reference axis for the hip-joint reaction force (Fig. 4) - taken from a biomechanics study of patients in single-legged stance. [31] In reality we have little or no understanding of which patient posture(s) will produce an edge-wear condition. Thus while the MOS-algorithm can indicate the safety margin in that cup design and with that diameter, it is likely that this is representative of the "ideal' patient (Fig. 3a). Thus mathematical treatments may underestimate the risk of edge-wear, particularly in young and active individuals (Fig. 3b).

The MOS-algorithm has provided the first demonstration that small cups inherently had the least margin of safety due to their wear-pattern angles being proportionally greater than in large cups. This tribo-mechanical effect was not intuitively obvious, considering that wear patterns increased in size with increased cup diameter. [29] However as shown by example, a $46 \mathrm{~mm}$ cup featured a larger wear-pattern angle than a $56 \mathrm{~mm}$ cup and thus the marginof-safety was reduced accordingly (Figs. 6, 8). Adding to the risk was the reduced coverage in some design of small cups (Fig. 7). Thus smaller cups inherently have smaller safety margins, a fact which has become well identified in clinical and retrieval studies. [1,8-10,18]

The dilemma apparent is that steep-cup algorithms (Fig. 9, 10) are based only on a scenario of adverse edgeloading during gait, i.e. in the habitual load-bearing area of the cup (Fig. 4). However the apparent desirability of positioning cups with reduced lateral-inclination may may result in other risks, such as posterior impingement, subluxation and anterior edge wear. $[1,32]$ In our patient with normal spine mobility, EOS imaging demonstrated that cup inclination steepened by $9^{\circ}$ in the seated position, with the margin-of-safety being reduced by $50 \%$. Thus the risk is that MOM impingement and subluxation while in sitting

\begin{tabular}{|c|l|l|l|l|l|l|l|l|l|l|l|l|l|}
\hline Diameter BHR-type & $\mathbf{3 6 m m}$ & $\mathbf{3 8 m m}$ & $\mathbf{4 0} \mathbf{m m}$ & $\mathbf{4 2} \mathbf{m m}$ & $\mathbf{4 4 m m}$ & $\mathbf{4 6 m m}$ & $\mathbf{4 8 m m}$ & $\mathbf{5 0 m m}$ & $\mathbf{5 2 m m}$ & $\mathbf{5 4 m m}$ & $\mathbf{5 6 m m}$ & $\mathbf{5 8 m m}$ & $\mathbf{6 0 m m}$ \\
\hline Inclination (L) & 50 & 50 & 50 & 50 & 50 & 50 & 50 & 50 & 50 & 50 & 50 & 50 & 50 \\
\hline Angle (A/2) & 33.4 & 33.4 & 33.4 & 33.4 & 33.4 & 33.4 & 33.4 & 33.4 & 33.4 & 33.4 & 33.4 & 33.4 & 33.4 \\
\hline Angle (P) & 11.3 & 11.0 & 10.7 & 10.3 & 10.0 & 9.7 & 9.4 & 9.1 & 8.7 & 8.4 & 8.1 & 7.8 & 7.4 \\
\hline $\mathrm{L}+\mathrm{P}$ & 61.3 & 61.0 & 60.7 & 60.3 & 60.0 & 59.7 & 59.4 & 59.1 & 58.7 & 58.4 & 58.1 & 57.8 & 57.4 \\
\hline $\mathrm{P}+\mathrm{A} / 2$ & 44.7 & 43.5 & 42.4 & 41.1 & 40.0 & 38.8 & 37.7 & 36.5 & 35.3 & 34.1 & 33.0 & 31.8 & 30.6 \\
\hline $\mathrm{L}+\mathrm{P}+\mathrm{A} / 2$ & 94.7 & 93.5 & 92.4 & 91.1 & 90.0 & 88.8 & 87.7 & 86.5 & 85.3 & 84.1 & 83.0 & 81.8 & 80.6 \\
\hline $\mathrm{MOS}\left(^{\circ}\right)$ & 9.3 & 10.5 & 11.6 & 12.9 & 14.0 & 15.2 & 16.3 & 17.5 & 18.7 & 19.9 & 21.0 & 22.2 & 23.4 \\
\hline $\mathrm{ARC}\left(^{\circ}\right)$ & 28.7 & 29.0 & 29.3 & 29.7 & 30.0 & 30.3 & 30.6 & 30.9 & 31.3 & 31.6 & 31.9 & 32.2 & 32.6 \\
\hline $\mathrm{CPR}\left(^{\circ}\right)$ & 42.7 & 43.0 & 43.3 & 43.7 & 44.0 & 44.3 & 44.6 & 44.9 & 45.3 & 45.6 & 45.9 & 46.2 & 46.6 \\
\hline $\mathrm{MOS}(\mathrm{mm})$ & 2.9 & 3.5 & 4.1 & 4.7 & 5.4 & 6.1 & 6.8 & 7.6 & 8.5 & 9.3 & 10.2 & 11.1 & 12.2 \\
\hline $\mathrm{ARC}(\mathrm{mm})$ & 8.9 & 9.5 & 10.1 & 10.8 & 11.4 & 12.0 & 12.7 & 13.3 & 14.0 & 14.7 & 15.4 & 16.1 & 16.8 \\
\hline $\mathrm{CPR}(\mathrm{mm})$ & 13.1 & 13.9 & 14.8 & 15.6 & 16.5 & 17.3 & 18.2 & 19.1 & 20.0 & 20.9 & 21.8 & 22.8 & 23.7 \\
\hline
\end{tabular}

Table 1. Sample calculations for BHR-type cups using $50^{\circ}$ cup inclination as an example, where equation- 2 indicates $M O S=104-(L+P+A / 2)$, equation-5 has $A R C=90-(L+P)$, and equation-6 has $C P R=104-(L+P)$ and from. Angular data were converted to distances using equations $8 a$ and $b$. 
or other postures could provoke rim-damage mechanisms. $[7,33,34]$ Such a release of large metal particles could then provoke an aggressive 3rd-body wear mechanism during gait. [20,34] These risks in implant orientation combined with patient positional variation are poorly understood. EOS imaging combined with the MOS-algorithm should help in the exploration of such postural variations.

In conclusion, the margin-of-safety algorithm demonstrated the risk factors inherent in 46-48mm BHR-type devices described in the June MHRA alert. The MOS-algorithm facilitated an understanding of how cup design, diameter and inclination affected the margin-of-safety. In patient studies the cup size and rim profile are pre-determined and thus the only input needed for ARC, CPR and MOS determinations is the cup's lateral inclination (Table 1). These data also indicated that cups with less steep inclinations $\left(45-55^{\circ}\right)$ effectively raised the available margin of safety, even in $46-48 \mathrm{~mm}$ size cups. It is hoped the MOSalgorithm will provide surgeons with a suitable instrument to evaluate how the MHRA warning affects their clinical practice.

\section{Disclosure Statement}

One or more of our authors have disclosed information that may present potential for conflict of interest with this work. For full disclosures refer to last page of this journal.

\section{References}

1. Langton DJ, Sprowson AP, Joyce TJ, Reed M, Carluke I, Partington P, Nargol AV. Blood metal ion concentrations after hip resurfacing arthroplasty: a comparative study of articular surface replacement and Birmingham Hip Resurfacing arthroplasties. J Bone Joint Surg Br 2009;91-10:1287-95.

2. Hart AJ, Sabah S, Henckel J, Lewis A, Cobb J, Sampson B, Mitchell A, Skinner JA. The painful metal-on-metal hip resurfacing. J Bone Joint Surg Br 2009;91-6:738-44.

3. Mabilleau G, Kwon YM, Pandit H, Murray DW, Sabokbar A. Metal-on-metal hip resurfacing arthroplasty: a review of periprosthetic biological reactions. Acta Orthop 2008;79-6:734-47.

4. Vendittoli PA, Mottard S, Roy AG, Dupont C, Lavigne M. Chromium and cobalt ion release following the Durom high carbon content, forged metal-on-metal surface replacement of the hip. J Bone Joint Surg Br 2007;89-4:441-8.

5. Kwon YM, Mellon SJ, Monk P, Murray DW, Gill HS. In vivo evaluation of edge-loading in metal-on-metal hip resurfacing patients with pseudotumours. Bone Joint Res. 2012;1-4:42 -9

6. Underwood RJ, Zografos A, Sayles RS, Hart A, Cann P. Edge loading in metal-on-metal hips: low clearance is a new risk factor. J Eng in Med 2012;226-3:217 - 6 .

7. McHugh D, Currier J, Kennedy F, Collier J, Van Critters D. Plastic Deformation from Edge Loading is common on Retrieved Metal-on-Metal Hips and Can Be Predicted With Finite Element Analysis. In: Kurtz SM, Greenwald SA, Mihalko WM, Lemons JA, eds. Metal-On-Metal Total Hip Replacement Devices, 2013:235-50.

8. Morlock MM, Bishop NE, Zustin J, Hahn M, Ruther W, Amling M. Modes of Implant Failure After Hip Resurfacing: Morphological and Wear Analysis of 267 Retrieval Specimens. J Bone Joint Surg Am 2008;90:89 -95.

9. De Haan R, Pattyn C, Gill HS, Murray DW, Campbell PA, De Smet K. Correlation between inclination of the acetabular component and metal ion levels in metal-on-metal hip resurfacing replacement. J Bone Joint Surg Br 2008;90-10:1291-7.

10. Jeffers JR, A, Taylor A, Tuke M. The problem with large diameter metal-on-metal acetabular cup inclination. Bulletin of the NYU Hospital for Joint Diseases 2009;67 -2:189 -92 .

11. Shimmin AJ, Walter WL, Esposito C. The influence of the size of the component on the outcome of resurfacing arthroplasty of the hip. Journal of Bone and Joint Surgery BR 2010;92 -B:469 - 76.
12. Griffin WL, Nanson CJ, Springer BD, Davies MA, Fehring TK. Reduced articular surface of one-piece cups. A cause of runaway wear and early failure. Clin Orthop Relat Res 2010;468:2328 - 32 .

13. Matharu GS, McBryde CW, Pynsent WB, Pynsent PB, Treacy RBC. The outcome of the Birmingham Hip Resurfacing in patients aged $<50$ years up to 14 years post-operatively. Bone Joint J 2013;95-B:1172-7.

14. De Smet K. Revisions of hip resurfacings from an independent specialist center. ISTA 28th Annual Congress. Vienna, Austria, 2015.

15. Daniel J. Mortality and implant revision rates following hip resurfacings and hip replacements. ISTA 28th Annual Congress. Vienna, Austria, 2015.

16. Leslie I, Williams S, Brown C, Isaac G, Jin Z, Ingham E, Fisher J. Effect of bearing size on the long-term wear, wear debris, and ion levels of large diameter metalon-metal hip replacements-An in vitro study. J Biomed Mater Res B Appl Biomater 2008;87-1:163-72.

17. Bowsher JG, Clarke IC, Williams PA, Donaldson TK. What is a "normal" wear pattern for metal-on-metal hip bearings? J Biomed Mater Res B Appl Biomater 2009;911:297-308.

18. Brodner W, Grubl A, Jankovsky R, Meisinger V, Lehr S, Gottsauner-Wolf F. Cup inclination and serum concentration of cobalt and chromium after metal-on-metal total hip arthroplasty. J Arthroplasty 2004;19-8 Suppl 3:66-70.

19. Wang L, Williams S, Udofia I, Isaac G, Fisher J, Zhongmin J. The effect of cup orientation and coverage on contact mechanics and range of motion of metal-on-metal hip resurfacing arthroplasty. J Eng in Med 2012;226-11:887-6.

20. Clarke IC, Burgett-Morena MD, Donaldson TK, Smith EJ, Savissar C, Bowsher JG Validation of clinical edge-wear in 'Steep-cups' using 40 - 70 degrees dynamic inclinations in novel MOM simulator study. ISTA 28th Annual Congress. Vienna, Austria, 2015.

21. Amstutz HC, Le Duff M, Johnson AJ. Socket position determines hip resurfacing 10year survivorship. Clinical Orthopaedics and Related Research 2012;470:3127 - 33.

22. Yoon JP, Le Duff MJ, Johnson A, Takamura KM, Ebramzadeh E, Amstutz CA. Contact patch to rim distance predicts metal ion levels in hip resurfacing. Clin Orthop Relat Res 2013;471:1615-21

23. Matthies AK, Henckel J, Cro S, Suarez A, Noble PC, Skinner J, Hart AJ. Predicting Wear and Blood Metal Ion Levels in Metal-on-Metal HIp Resurfacing. J Orthop Res 2014;32-1:167-74.

24. Lazennec JY, Rousseau MA, Rangel A, Gorin M, Belicourt C, Brusson A, Catonne Y Pelvis and total hip arthroplasty acetabular component orientations in sitting and standing positions: measurements reproductibility with EOS imaging system versus conventional radiographies. Orthop Traumatol Surg Res 2011;97-4:373 - 80.

25. Lazennec JY, Rousseau MA, Brusson A, Folinais D, Amel M, Clarke IC, Pour AE. Total Hip Prostheses in Standing, Sitting and Squatting Positions: An Overview of Our 8 Years Practice Using the EOS Imaging Technology. Open Orthop. J. 2015;9:26-44.

26. Lee R, Essner A, Wang A. Tribological considerations in primary and revision metalon-metal arthroplasty. J Bone Joint Surg Am 2008;90 Suppl 3:118-24.

27. Clarke IC, Donaldson TK, Savisaar C, Bowsher JG. New algorithm permits accurate depiction of cup-wear patterns in clinical and simulator studies. ISTA 28th Annual Congress. Vienna, Austria, 2015

28. Bengs BC, Sangiorgio SN, Ebramzadeh E. Less range of motion with resurfacing arthroplasty than with total hip arthroplasty. Acta Orthop 2008:79-6:755-62.

29. Clarke IC, Donaldson TK, Burgett MD, Smith EJ, Bowsher J, Savisaar C, John A, Lazennec JY, McPherson E, Peters CL. Normal and Adverse Wear Patterns Created In-vivo on MOM Surfaces - a retrieval study representing four vendors. In: Kurtz SM, Greenwald SA, Mihalko WM, Lemons JA, eds. Metal-on-Metal Total Hip Replacement Devices. Vol. STP1560. West Conshohocken, PA: ASTM International, 2013 157-92.

30. Langton, DJ, Jameson, SS, Joyce, TJ, Gandhi, JN, Sidaginamale, R, Mereddy, P, Lord, J, Nargol, AV. Accelerating failure rate of the ASR total hip replacement J. Bone Joint Surg. Br 2011; 93-8: 1011 - 1016.

31. Bergmann G, Deuretzbacher G, Heller M, Graichen F, Rohlmann A, Strauss J, Duda GN. Hip contact forces and gait patterns from routine activities. J Biomech 2001;347:859-71.

32. Esposito CI, Walter WL, Roques A, Tuke MA, Zicat BA, Walsh WR, Walter WK. Wear in alumina-on-alumina ceramic bearings. A retrieval analysis of edge loading. J Bone Joint Surg Am 2012;7:901-7.

33. Halim T, Burgett M, Donaldson TK, Savisaar C, Bowsher JG, Clarke IC. Profiling the third-body wear damage produced in $\mathrm{CoCr}$ surfaces by bone cement, $\mathrm{CoCr}$, and Ti6A14V debris: A 10-cycle metal-on-metal simulator test. J Eng in Med 2014;Proc. IMechE -H:1-11.

34. Halim T, Clarke IC, Burgett-Moreno M, Donaldson TK, Savisaar C, Bowsher JG. A Simulator Study of Adverse Wear with Metal and Cement Debris Contamination in metal-on-metal (MOM) Hip Bearings. J Bone Joint Research (UK) 2015;4:29-3 


\section{Glossary of Terms}

A:

Angle used to represent cup wear-pattern

C:

Angle used to represent size of contact-patch

F:

Angle describing the sub-hemispherical bearing surface

P:

Profile angle representing loss of bearing surface in loadbearing region of cup

L:

Lateral inclination angle of cup

*L:

Critical cup inclination (equation-4)

ARC:

Distance measured from cup rim to the vertical plane, analogous to the "Arc of Cover" [9]

CAP:

Area of cup wear-pattern produced in a hip simulator
CPR:

"Contact Patch to Rim" chord distance from cup rim to a $14^{\circ}$ medially-directed axis [1]

\section{CPER:}

"Contact Patch Edge to Rim" chord distance [6] measured from cup rim to edge of contact patch (as centered on a $14^{\circ}$ medially-directed axis)

Edge wear:

An adverse wear condition produced when the cup rim is able to cross the habitual wear-pattern in a MOM bearing

EW\%:

definition for edge wear in MOS-algorithm (equation-3)

Margin-of-safety:

A narrow region that can be present between cup rim and the edge of the wear-pattern

MOS:

Margin-of-safety measurement (distance, angle: equations 2 and $8 \mathrm{a})$

Wear-pattern:

Habitual wear zone produced by patient's hip function

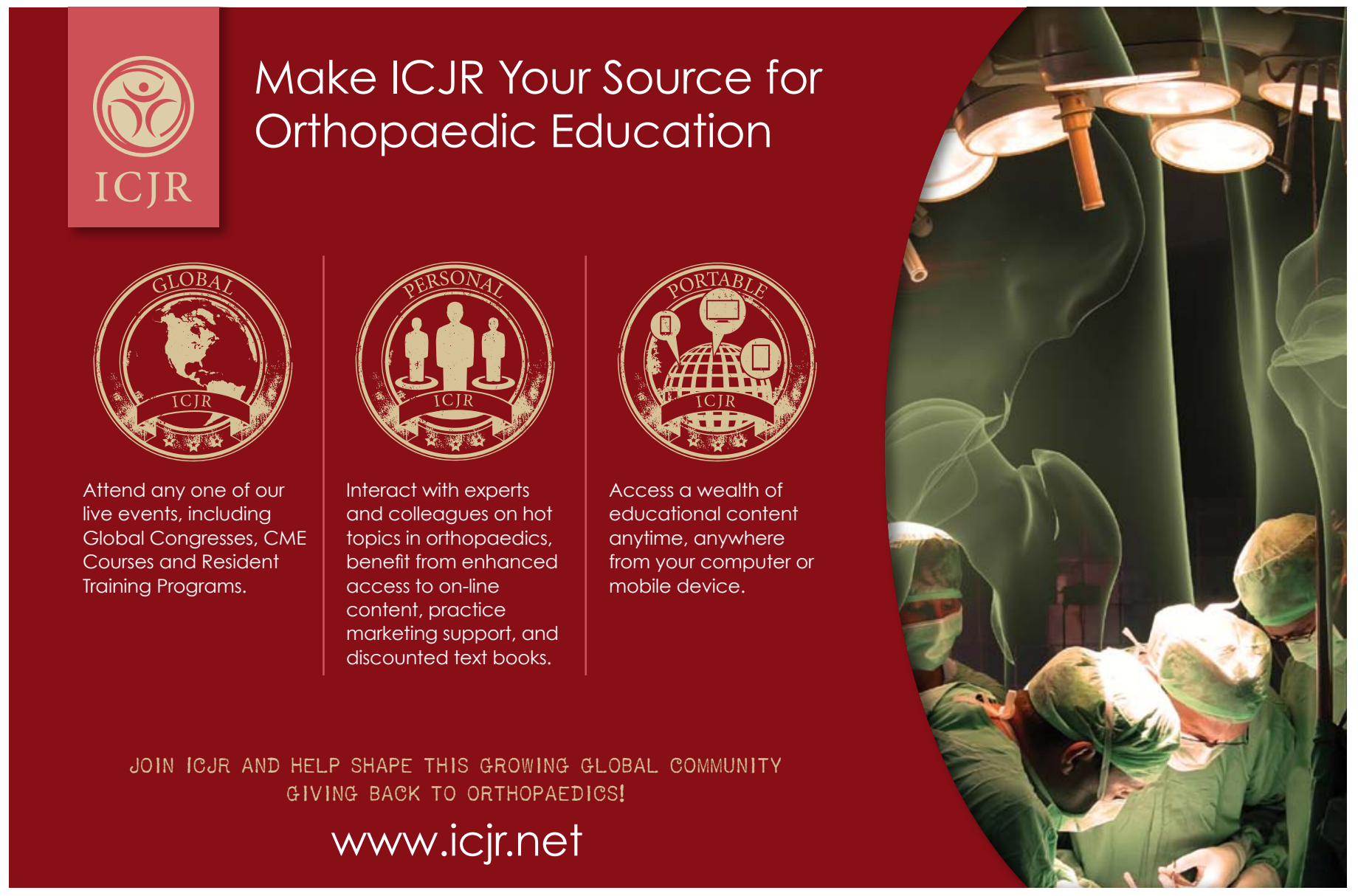

